\title{
Características sociodemográficas, clínicas e histopatológica de pacien- tes com carcinoma epidermóide de lábio: uma análise retrospectiva
} (1997-2004)

\section{Sociodemographic, clinical and histopathological features for lip squa- mous cell carcinoma patients: a retrospective analysis (1997-2004)}

\author{
Marina F. de Sena ${ }^{1}$, Anna Paula S. da Costa ${ }^{1}$, Maria Ângela Fernandes Ferreira ${ }^{2}$
}

\begin{abstract}
RESUMO
Modelo do estudo: Transversal retrospectivo. Objetivo: Descrever as características sociodemográficas, clínicas e histopatológicas dos pacientes com carcinoma epidermóide de lábio atendidos no Hospital Dr. Luiz Antônio (Natal-RN) nos anos de 1997 a 2004. Metodologia: Foram examinados 173 prontuários e coletadas informações referentes a idade, cor, escolaridade, exposição do indivíduo a fatores de risco (tabaco, álcool e exposição solar) e as características clínicas e histológicas (localização anatômica, diâmetro e estadiamento clínico e histológico, extensão do tumor e graduação histológica de malignidade). Os dados foram apresentados de maneira descritiva por meio de números absolutos, percentuais, medidas de tendência central e de variabilidade. Resultados: A média de idades dos pacientes foi de 66,55 anos, com predomínio do sexo masculino (69,36\%), indivíduos com baixo nível de escolaridade $(67,08 \%)$, histórico de hábito tabagista $(89,58 \%)$ e atividade ocupacional relacionada à exposição solar $(64,64 \%)$. Foi contatada uma maior frequência de carcinoma epidermóide moderadamente diferenciado $(79,76 \%)$, no lábio inferior $(78,61 \%)$, lesões com até $2 \mathrm{~cm}$ de diâmetro $(52,33 \%)$ e no estadiamento inicial. Conclusão: As lesões de câncer de lábio foram predominantemente localizadas e de baixa malignidade, prevalecendo em indivíduos do sexo masculino, idosos e com baixo nível de escolaridade. A presença de exposição aos fatores de risco, raios ultravioleta e fumo, deve ser considerada nesta população.
\end{abstract}

Palavras-Chaves: Neoplasias Labiais. Epidemiologia. Registros Médicos.

1. Mestre em Odontologia Preventiva e Social, Universidade Federal do Rio Grande do Norte, Departamento de Odontologia, Programa de Pós-Graduação em Odontologia Preventiva e Social

2. Professora Doutora do Programa de Pós-graduação em Odontologia Preventiva e Social, Universidade Federal do Rio Grande do Norte.
Correspondência: Marina Fernandes de Sena. Programa de Pós-Graduação em Odontologia Preventiva e Social Av Senador Salgado Filho 1787 - Lagoa Nova CEP: 59056000 - Natal (RN) Brasil Fone: $\left(0^{* *} 84\right) 32154134$ E-mail: marinafsena@yahoo.com.br

Artigo recebido em 31/08/2012 Aprovado para publicação em 21/03/2013

Conflito de Interesses: Nada a declarar. 


\section{Introdução}

Estudos relacionados ao câncer despertam o interesse da comunidade científica, profissionais da área e da população em geral, em virtude da crescente incidência desta enfermidade no mundo, consistindo em um problema de saúde pública. Tal importância pode ser evidenciada a partir de dados do INCA, visto que 14.170 novos casos de câncer da cavidade oral foram estimados, no Brasil, para 2012. Na região Nordeste a estimativa é de 2550 novos casos e, no Rio Grande do Norte, 190 novos casos. ${ }^{1}$

O câncer de lábio é a neoplasia maligna mais frequente da cavidade oral, ${ }^{2}$ provavelmente devido esta localização anatômica ser mais facilmente diagnosticada. A exposição crônica à radiação ultravioleta é o fator de risco mais frequente entre 46,93 e $76 \%{ }^{4}$ dos casos de carcinoma epidermóide de lábio. No entanto, essa patologia apresenta um bom prognóstico com taxa de sobrevida em torno de $98 \%$. $^{2}$

O prognóstico favorável nesse tipo de neoplasia pode decorrer da maior frequência dos tumores com tamanho menor que dois $\mathrm{cm}$ no exame clínico inicial ${ }^{5}$ e ausência de linfonodos palpáveis, ${ }^{6}$ os quais são indicativos de um diagnóstico realizado precocemente. No entanto, surgimento de recidiva local, após o tratamento, é registrado na literatura em torno de 4,97-15,3\%. ${ }^{3}$ A frequência de metástase em linfonodo varia entre $5,38-32,2 \%{ }^{3}$ Em relação ao aparecimento de metástase à distância, observa-se baixa frequência $(07-5,4 \%){ }^{9}$

Desse modo, embora o prognóstico do câncer labial seja bastante favorável, tal enfermidade pode trazer repercussões na qualidade de vida dos pacientes em virtude das possíveis alterações funcionais e estéticas. Nesse sentido, torna-se necessário investigar as características dos pacientes com câncer de lábio no Estado do Rio Grande do Norte em virtude da presença do elevado índice de raio ultravioleta ${ }^{10}$ que consiste em um dos principais fatores etiológicos do câncer de lábio.

Assim, o objetivo do presente estudo consistiu em conhecer os fatores sociodemográficos e clínicos dos pacientes com carcinoma epidermóide de lábio atendidos no Hospital Dr. Luiz Antônio (Natal-RN) no período entre 1997 a 2004.

\section{Metodologia}

Um total de 173 pacientes com diagnóstico de carcinoma epidermóide de lábio foi avaliado a partir do banco de dados do Hospital Dr. Luiz Antônio (Natal-RN), centro de referência para tratamento de câncer no estado do Rio Grande do Norte. As informações coletados foram os seguintes: sexo, idade ( $<50$ anos, 50-70 anos e $>70$ anos), cor da pele (branco, pardo), escolaridade (analfabeto $/ 1^{\circ}$ incompleto e acima do $1^{\circ}$ completo) e exposição aos fatores de risco (tabagismo, etilismo e atividade ocupacional relacionada à exposição solar).

Quanto aos parâmetros clínicos foram anotados a localização anatômica do tumor (lábio inferior, lábio superior, envolvimento de comissura), diâmetro clínico do tumor (até $2 \mathrm{~cm}, 2$ até $4 \mathrm{~cm}$ e acima de 4 $\mathrm{cm}$ ), diâmetro histológico do tumor (até $2 \mathrm{~cm}, 2$ até 4 $\mathrm{cm}$ e acima de $4 \mathrm{~cm}$ ), estadiamento clínico - TNM (Estádio I, Estádio II, Estádio III, Estádio IV), estadiamento patológico - pTNM (Estádio I, Estádio II, Estádio III, Estádio IV), extensão da lesão (localizada e metástase regional) e graduação histológica (bem diferenciado, moderadamente diferenciado, mal diferenciado).

As variáveis foram apresentadas de maneira descritiva por meio de números absolutos, proporções, medidas de tendência central e de variabilidade. Para a análise dos dados foi utilizado o programa estatístico SAS (SAS Institute Inc. Cary, NC, USA). O projeto foi aprovado pelo Comitê de Ética do Hospital Dr. Luiz Antônio (Natal-RN) sob o número 034/034/2007.

\section{Resultados}

A distribuição do número de casos de câncer de lábio demonstra um aumento percentual anual no período de 1997 a 2004 (Figura 1). A idade média foi de 66,86 anos (desvio padrão $=15,72$ ) com maior frequência para a idade acima de 70 anos $(47,97 \%)$, pardos $(66,66 \%)$ sendo, predominantemente, indivíduos do sexo masculino $(69,36 \%)$ e analfabetos $(67,08 \%)$ (Tabela 1).

Em relação ao comportamento de risco observou-se maior predominância de indivíduos fumantes $(89,58 \%)$ e que realizavam atividades relacionadas à exposição solar $(64,64 \%)$ (Tabela 1$)$.

Concernente às características do tumor, obteve-se uma maior frequência no lábio inferior $(78,61 \%)$, em lesões com até $2 \mathrm{~cm}$ de diâmetro (52,33\%). Em relação ao estadiamento clínico, a maioria dos casos apresentou-se no estádio I (42,74\%), detectando-se uma frequência de $92,89 \%$ de tumores com extensão localizada no início do diagnóstico inicial (Tabela 2). 


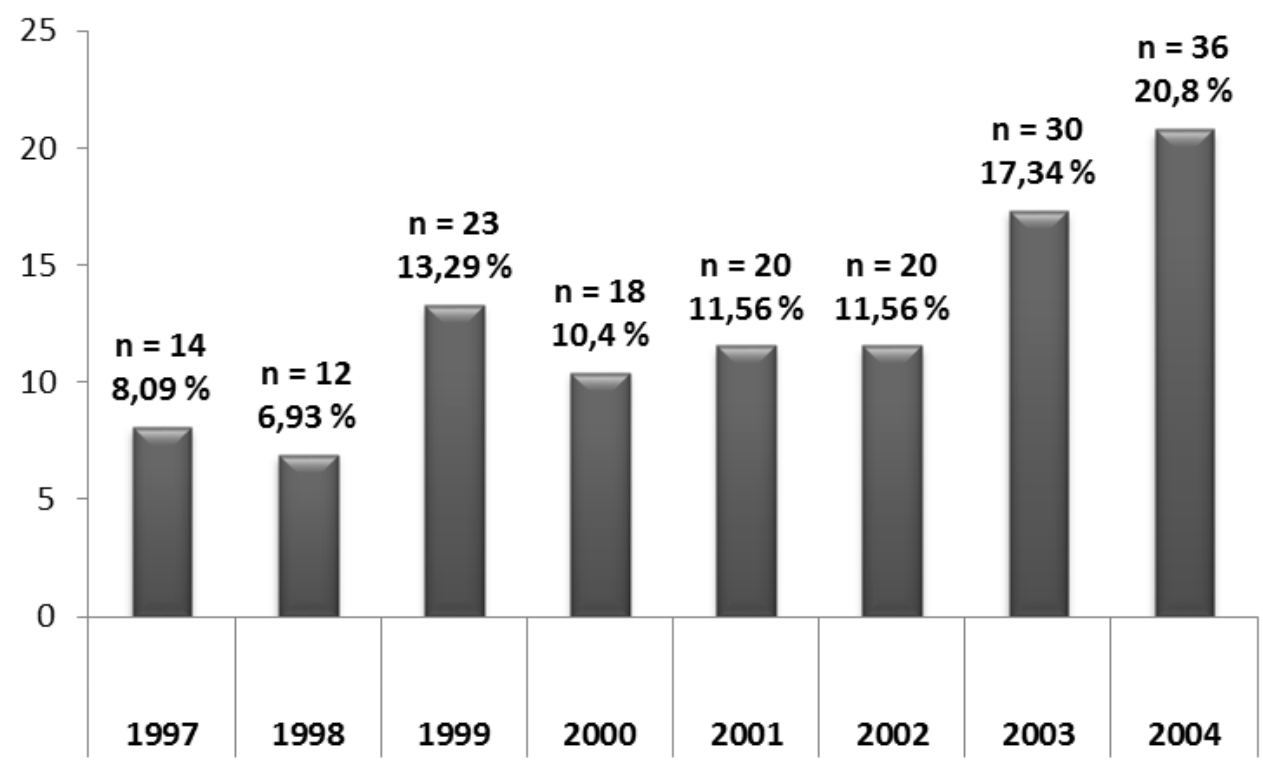

Figura 1. Distribuição dos casos de câncer de lábio registrados no período de 1997-2004 no Hospital Dr. Luiz Antônio. Natal/RN (N = 173).

\section{Tabela 1}

Caracterização sócio-demográfica, geográfica e dos hábitos dos pacientes com câncer de lábio do Hospital Luiz Antônio (N=173). Natal - RN, 1997-2004.

\begin{tabular}{|c|c|c|c|}
\hline & $\mathrm{n}^{\mathrm{o}}$ & $\%$ & EP* \\
\hline \multicolumn{4}{|l|}{ Idade } \\
\hline$<50$ & 27 & 15,60 & 2,76 \\
\hline $50-70$ & 63 & 36,41 & 3,66 \\
\hline$>70$ & 83 & 47,97 & 3,80 \\
\hline \multicolumn{4}{|l|}{ Sexo } \\
\hline Masculino & 120 & 69,36 & 3,51 \\
\hline Feminino & 53 & 30,63 & 3,51 \\
\hline \multicolumn{4}{|l|}{ Etnia } \\
\hline Branca & 39 & 33,33 & 4,37 \\
\hline Parda & 78 & 66,66 & 4,37 \\
\hline \multicolumn{4}{|l|}{ Escolaridade } \\
\hline Analfabeto & 53 & 67,08 & 5,32 \\
\hline $1^{\circ} \mathrm{Grau}$ Incompleto & 22 & 27,84 & 5,07 \\
\hline Grau de escolaridade superior ao $1^{\circ}$ Grau Completo & 4 & 5,06 & 2,48 \\
\hline \multicolumn{4}{|l|}{ Tabagismo } \\
\hline Sim & 86 & 89,58 & 3,13 \\
\hline Não & 10 & 10,41 & 3,13 \\
\hline \multicolumn{4}{|l|}{ Etilismo } \\
\hline Sim & 22 & 50,0 & 7,62 \\
\hline Não & 22 & 50,0 & 7,62 \\
\hline \multicolumn{4}{|l|}{ Ocupação } \\
\hline Relacionada à exposição solar & 64 & 64,64 & 4,82 \\
\hline Não relacionada à exposição solar & 35 & 35,35 & 4,82 \\
\hline
\end{tabular}

${ }^{*}=$ Erro Padrão 


\section{Tabela 2}

Características clínicas e histopatológicas dos pacientes com câncer de lábio do Hospital Luiz Antônio. Natal RN, 1997-2004 (N=173).

\begin{tabular}{|c|c|c|c|}
\hline & $\mathrm{N}^{\circ}$ & $\%$ & EP* \\
\hline \multicolumn{4}{|l|}{ Localização Anatônica } \\
\hline Lábio Inferior & 136 & 78,61 & 3,12 \\
\hline Lábio Superior & 12 & 6,93 & 1,93 \\
\hline Lábio Superior e Inferior & 2 & 1,15 & 0,81 \\
\hline Envolvimento de comissura & 23 & 13,29 & 2,58 \\
\hline \multicolumn{4}{|l|}{ Diâmetro da Lesão Exame Clínico } \\
\hline até $2 \mathrm{~cm}$ & 56 & 52,33 & 4,85 \\
\hline de 2 a $4 \mathrm{~cm}$ & 42 & 39,25 & 4,74 \\
\hline acima de $4 \mathrm{~cm}$ & 9 & 8,41 & 2,69 \\
\hline \multicolumn{4}{|l|}{ Diâmetro da Lesão Histopatológico } \\
\hline até $2 \mathrm{~cm}$ & 70 & 43,20 & 3,90 \\
\hline de $2 \mathrm{a} 4 \mathrm{~cm}$ & 68 & 41,97 & 3,88 \\
\hline acima de $4 \mathrm{~cm}$ & 24 & 14,81 & 2,79 \\
\hline \multicolumn{4}{|l|}{ TNM (Estadiamento Clínico) } \\
\hline Estádio I & 56 & 42,74 & 4,33 \\
\hline Estádio II & 32 & 24,42 & 3,76 \\
\hline Estádio III & 24 & 18,32 & 3,39 \\
\hline Estádio IV & 19 & 14,50 & 3,08 \\
\hline \multicolumn{4}{|l|}{ pTNM (Estadiamento Patológico) } \\
\hline Estádio I & 71 & 43,29 & 3,88 \\
\hline Estádio II & 55 & 33,53 & 3,69 \\
\hline Estádio III & 22 & 13,41 & 2,66 \\
\hline Estádio IV & 16 & 9,75 & 2,32 \\
\hline \multicolumn{4}{|l|}{ Extensão da lesão } \\
\hline Localizada & 157 & 92,89 & 1,98 \\
\hline Metástase Regional & 12 & 7,10 & 1,98 \\
\hline \multicolumn{4}{|l|}{ Graduação Histológica de Malignidade } \\
\hline Carcinoma epidermóide bem diferenciado & 26 & 15,02 & 2,72 \\
\hline Carcinoma epidermóide moderadamente diferenciado & 138 & 79,76 & 3,06 \\
\hline Carcinoma epidermóide mal diferenciado & 9 & 5,20 & 1,69 \\
\hline
\end{tabular}

* $=$ Erro padrão

Os achados histopatológicos da lesão demonstram uma maior frequência de tumores com até dois cm de diâmetro (43,20\%), maior frequência de lesões em estádio inicial (estádio I) $(43,29 \%)$, apresentando a maioria dos casos de graduação histológica de malignidade moderadamente diferenciado $(79,76 \%)$ (Tabela 2).

\section{Discussão}

Os dados obtidos, no presente estudo, para câncer de lábio foram distintos do número de casos de câncer de lábio apresentados no Registro de Câncer de Base Populacional (RCBP) de Natal. As informações presentes no RCBP, no período de 1999-2004, corresponderam a 26 casos de câncer de lábio, ${ }^{11}$ enquanto que nos registros do Hospital Dr. Luiz Antônio o número de casos, para este mesmo período totalizaram 129. O equívoco no momento da classificação topográfica do câncer, registrando-o como de pele, poderia ser um fator associado à diferença no número de casos apresentados.

Em relação aos fatores sociodemográficos, foi observado uma maior frequência de câncer de lábio 
em homens idosos e com baixo nível de escolaridade. Indivíduos com menor escolaridade apresentam comportamentos de risco que os deixam mais susceptíveis no desenvolvimento de doenças, podendo-se citar o inquérito realizado em dezesseis capitais brasileiras que encontrou, por exemplo, maior prevalência de tabagismo nos grupos populacionais de menor escolaridade. ${ }^{12}$

A maior frequência dessa neoplasia em indivíduos do sexo masculino está de acordo com os dados epidemiológicos encontrados na literatura. ${ }^{3,9,13,14} \mathrm{~A}$ menor frequência no sexo feminino pode ser em virtude das mulheres apresentarem como comportamento natural o uso de cosméticos no lábio (batom) que apresenta efeito protetor, como também o fato de participarem menos de atividades ocupacionais relacionadas à exposição solar. ${ }^{3}$

No entanto, análise de incidência em muitas partes do mundo vem mostrando declínio de câncer labial no sexo masculino. ${ }^{15}$ A mudança observada no perfil epidemiológico pode ser devida a maior consciência da população relacionada aos perigos da exposição ao sol, com o uso de agentes protetores; diminuição do hábito tabagista, com destaque ao fumo de cachimbo; na redução de indivíduos com atividades ocupacionais que implicavam em exposição ao sol e migração de populações rurais para urbanas durante as últimas décadas. ${ }^{16}$

Quanto ao perfil etário dos pacientes, foi constatada uma predominância de pacientes acima de 60 anos, verificando-se que a maior parte dos casos de câncer acontece em uma idade média entre 65-70 anos. ${ }^{3,13,14}$ Com o avanço da idade há um aumento nas taxas de incidência do câncer de lábio, ${ }^{16}$ visto que há o efeito cumulativo à exposição de agentes físicos (radiação solar) e químicos (tabaco, álcool). De fato, este resultado reforça as implicações fisiológicas advindas da idade, sendo de fundamental importância o controle e prevenção precoce das doenças crônicas a fim de evitar as complicações futuras associadas com o avanço da idade. ${ }^{17}$

Condizente às características étnicas, o presente estudo observou maior percentual de câncer de lábio em indivíduos pardos. Tal resultado pode se dever ao fato da população do estado do Rio Grande do Norte, segundo dados do censo demográfico 2000, apresentar maior proporção de pardos em relação a de brancos. ${ }^{18}$

Quanto aos hábitos deletérios relacionados ao desenvolvimento dessa lesão, foi encontrado um elevado percentual de indivíduos com câncer de lábio que apresentaram exposição ao tabaco. $\mathrm{O}$ contato dos produtos presentes no cigarro ou cachimbo na região labial podem consistir em fator que possibilitem maior risco de lesões malignas. ${ }^{14,19,20}$ Vale destacar que o hábito tabagista é considerado um problema de saúde pública, visto que segundo a Organização Mundial de Saúde (OMS) estima que de 2000 a 2030 o número de mortes anuais atribuíveis ao tabagismo aumentará de 4,9 para 10 milhões. ${ }^{21}$

Ainda na observação dos hábitos, deve-se apontar os resultados referentes ao etilismo posto que pode haver uma interação entre o consumo de álcool e o hábito de repousar o cigarro na boca. ${ }^{19}$ Os achados referentes a esse hábito foram inferiores ao do tabagismo, no entanto, há um viés de informação na medida em que envolve certo constrangimento por parte dos pacientes em relatar o hábito etilista.

Em relação ao tabagismo e etilismo, não foi possível extrair dados referentes à quantidade de cigarros, frequência de realização e questões referentes ao tipo de cigarro (com ou sem filtro, artesanal ou industrializado) ou ao tipo de bebida (teor alcoólico, bebida destilada), porque nos prontuários havia apenas a informação se o paciente era ou foi fumante e/ ou etilista.

No que se refere à exposição aos raios ultravioleta, a forte relação entre exposição solar e câncer labial é verificada em função da presença de uma alta proporção de mutações em lesões cancerígenas labiais no gene p53, que é característico dos danos no DNA induzidos pela luz ultravioleta. ${ }^{22}$ Estudos epidemiológicos verificam uma elevada frequência de indivíduos com lesões labiais submetidos a tal fator, $3,4,23$ sendo este maior contato com os raios solares em virtude de atividades ocupacionais ao ar livre. ${ }^{8,23}$

O elevado índice de radiação ultravioleta no Rio Grande do Norte ${ }^{12}$ remete a uma maior preocupação para conhecer o perfil epidemiológico de enfermidades relacionadas a tal fator etiológico. Diante dessa realidade climática do estado foi constatado, no presente estudo, um elevado percentual de indivíduos que apresentavam atividade ocupacional exposta ao sol, sendo a maioria agricultores. Embora os achados destaquem a profissão dos trabalhadores rurais, vale ressaltar também a presença de comerciantes informais que trabalham nas praias expostos ao sol, os quais apresentam elevada prevalência de lesões orais e periorais. $^{23}$

O câncer de lábio, na maioria dos relatos encontrados na literatura, apresenta-se no diagnóstico inicial com características clínicas e histológicas em 
estágio precoce, ${ }^{14,17}$ posto que por ser uma lesão externa e relacionada com a estética da face, há um maior esforço dos pacientes em procurar o profissional de saúde para sanar esta condição.

Um importante parâmetro para analisar o nível de comprometimento e avanço do tumor consiste na classificação de acordo com o TNM. Os resultados obtidos mostraram um menor percentual de casos no estágio IV, estando tanto o TNM como o pTNM situado na margem da frequência encontrada na literatura entre $4,41^{24}$ a $15,5 \% .^{25}$

Em relação aos achados referentes às lesões de câncer, foi registrado o seu tamanho clinico, bem como o da peça patológica a fim de possuir o maior número de dados possíveis para as variáveis a serem avaliadas. Os achados pertinentes a esta variável apontaram uma frequência de tumores com diâmetro superior a $4 \mathrm{~cm}$, acima daqueles encontrados na literatura. ${ }^{26}$ As características sociais dos pacientes atendidos no hospital, de baixa condição socioeconômica e educacional e com dificuldade de acesso ao serviço de saúde, parece explicar o diagnóstico em um estágio mais tardio da doença. ${ }^{8}$

No que condiz à localização anatômica, observa-se maior acometimento do lábio inferior, ${ }^{7,14}$ destacando-se como lesões de maior agressividade as comissurais, ${ }^{8}$ provavelmente devido os tumores que envolvem este sub-sítio apresentarem um maior tamanho.

Considerando as lesões comissurais, a literatura registra uma frequência que varia entre $0,7^{13}$ $8,4 \%,{ }^{8}$ encontrando-se neste estudo um percentual superior a estes relatos. O perfil aparentemente mais agressivo de lesões comissurais em contribuir como um fator para o desenvolvimento de recidivas se deve mais ao tamanho da lesão do que propriamente a localização do tumor.

Concernente ao grau histológico, os relatos da literatura mostram uma predominância de carcinomas com graduação bem diferenciada ${ }^{7,9,16,17}$ cujas células apresentam com menos anomalias morfológicas e funcionais, acarretando em um melhor prognóstico. Um menor percentual de lesões labiais em grau histológico bem diferenciado foi observado, mas apenas $5 \%$ de casos foram considerados mal diferenciados, estando na margem dos valores encontrados em outros estu$\operatorname{dos}\left(2,1^{16}-26,9 \%{ }^{8}\right)$.

Desta forma, mesmo diante das limitações inerentes aos estudos retrospectivos, em função da ausência de algumas informações, tais achados podem contribuir para o planejamento das atividades do hospital. Valendo ressaltar a necessidade de documentar e registrar os casos com maior detalhamento a fim de obter informações que facilitem a pesquisa nesta área, principalmente nos estudos retrospectivos que são de fácil execução e fornece uma riqueza de dados da patologia a ser pesquisada.

\section{Conclusão}

De acordo com o presente estudo pode-se concluir que câncer de lábio acometeu maior número de indivíduos do sexo masculino, na sexta década de vida e com desprivilegiados indicadores sociais como o baixo nível de escolaridade.

O hábito tabagista e a exposição solar estiveram apresentados em alta frequência na população estudada, sugerindo-se a necessidade de execução de práticas educativas e preventivas, destacando-se a importância do controle do consumo de tabaco.

De acordo com as características clínicas, a localização anatômica mais acometida foi o lábio inferior, cujas lesões foram em sua maioria detectadas em estágio inicial. Dentre as características histológicas destaca-se o elevado percentual de lesões moderadamente diferenciadas.

Por meio deste levantamento, observou-se a necessidade da existência de investigação mais aprofundada sobre a qualidade dos registros do RCBP de Natal.

\section{ABSTRACT}

Design of the study: Cross-sectional retrospective. Objective: To describe demographic, clinical and histopathological features of patients diagnosed with lip squamous cell carcinoma and treated at the Dr. Luiz Antônio Hospital (Natal-RN, Brazil) in the period of 1997 to 2004. Methodology: 173 records were examined and information related to age, skin color, education, and individual's exposure to risk factors (tobacco, alcohol and sun exposure), and clinical and histopathologic features (anatomical location of tumor, tumor diameter, tumor staging, extent of lesion and histopathological grading) were collected. Descriptive analysis was performed using absolute numbers, percentages, measures of central tendency and variability. Statistical analysis was performed using the SAS statistical software package (SAS 
Institute Inc. Cary, NC, USA). Results: The mean age was 66.55 years with male preference (69.36\%), individuals with low education level $(67.08 \%)$, history of smoking (89.58\%) and occupational activity related to sun exposure $(64.64 \%)$. Concerning the characteristics of the tumor, we obtained a greater frequency in the lower lip (78.61\%), in lesions with $2 \mathrm{~cm}(52.33 \%)$ at initial stages. Conclusion: The lesions of lip cancer were localized, with low malignancy, occurring in higher frequency in males, elderly and low educational level. The presence of exposure to risk factors, ultraviolet rays and smoking, must be considered in this population.

Key words: Lip Neoplasms. Epidemiology. Medical Records.

\section{Referências}

1. Instituto Nacional de Câncer [homepage]. Estimativa /2012 Incidência de Câncer no Brasil. Rio de Janeiro, 2011 [citado 07 dez. 2012]. Disponível em: http://www.inca.gov.br/estimativa/2012/.

2. McCombe D, MacGill K, Ainslie J, Beresford J, Matthews J. Squamous cell carcinoma of the lip: a retrospective review of the Peter MacCallum Cancer Institute experience 197988. Aust N Z J Surg 2000; 70: 358-61.

3. Luna-Ortiz K, Güemes-Meza A, Villavicencio-Valencia V, Mosqueda-Taylor. A Lip cancer experience in Mexico. An 11-year retrospective study. Oral Oncol 2004; 40: 992-9.

4. Wilson R, Jackson J, Rassekh C. A study of squamous cell carcinoma of the lip at West Virginia University Hospitals from 1980-2000. W V Med J 2005; 101: 217-9.

5. Abreu MAMM, Pimentel DRN, Silva OMP, Blachman IT, Michalany NS, Hirata $\mathrm{CH}$, et al. Carcinoma espinocelular do lábio: avaliação de fatores prognósticos. Rev Bras Otorrinolaringol 2004; 70: 765-70.

6. Antunes AA, Antunes AP. Estudo retrospectivo e revisão de literatura dos tumores dos lábios: experiência de 28 anos. Rev Bras Cancerol.. 2004; 50: 295 - 300.

7. de Visscher JG, van den Elsaker K, Grond AJ, van der Wal JE, van der Waal I. Surgical treatment of squamous cell carcinoma of the lower lip: evaluation of long-term results and prognostic factors--a retrospective analysis of 184 patients. J Oral Maxillofac Surg 1998; 56: 814-20.

8. Bilkay U, Kerem H, Ozek C, Gundogan H, Guner U, Gurler T, et al. Management of lower lip cancer: a retrospective analysis of 118 patients and review of the literature. Ann Plast Surg 2003; 50: 43-50.

9. Veness MJ, Ong C, Cakir B, Morgan G. Squamous cell carcinoma of the lip. Patterns of relapse and outcome: Reporting the Westmead Hospital experience, 1980-1997. Australas Radiol 2001; 45: 195-9.

10. Silva FR. Estudo da radiação ultravioleta na Cidade de NatalRN [dissertação]. Natal: Universidade Federal do Rio Grande do Norte; 2008.

11. Instituto Nacional de Câncer [homepage]. Brasília (DF): Registro de Câncer de Base Populacional, 2012 [citado 07 dez. 2012]. Disponível em: http://www2.inca.gov.br/wps/wcm/ connect/estatisticas/site/home/rcbp/.

12. Brasil. Ministério da Saúde. Secretaria de Vigilância em Saúde. Secretaria de Atenção à Saúde. Instituto Nacional de Câncer. Coordenação de Prevenção e Vigilância. Inquérito domiciliar sobre comportamentos de risco e morbidade referida de doenças e agravos não transmissíveis: Brasil, 15 capitais e Distrito Federal, 2002-2003. Rio de Janeiro: INCA, 2004.

13. Zitsch RP, Park CW, Renner GJ, Rea JL. Outcome analysis for lip carcinoma. Otolaryngol Head Neck Surg. 1995; 113: 589-96.
14. Maruccia M, Onesti MG, Parisi P, Cigna E, Troccola A, Scuderi N. Lip cancer: a 10-year retrospective epidemiological study. Anticancer Res 2012; 32: 1543-6.

15. Moore S, Johnson N, Pierce A, Wilson D. The epidemiology of lip cancer: a review of global incidence and aetiology. Oral Dis. 1999; 5:185-95.

16. de Visscher JG, Schaapveld M, Otter R, Visser $O$, van der Waal I. Epidemiology of cancer of the lip in The Netherlands. Oral Oncol 1998; 34: 421-6.

17. Géraud C, Koenen W, Neumayr L, Doobe G, Schmieder A, Weiss C, Goerdt S, Faulhaber J. Lip cancer: retrospective analysis of 181 cases. J Dtsch Dermatol Ges. 2012; 10:1217.

18. Instittuto Brasileiro de Geografia e Estatística (IBGE). Tendências demográficas. [citado 15 Dez 2012]. Disponível em: http://www.ibge.gov.br/home/estatistica/populacao/ tendencia_demografica/analse_populacao/1940_2000/ tabela07.pdf

19. Perea-Milla López E, Miñarro-Del Moral RM, Martínez-García C, Zanetti R, Rosso S, Serrano S, Aneiros JF, Jimenez-Puente A, Redondo M. Lifestyles, environmental and phenotypic factors associated with lip cancer: a case-control study in southern Spain. Br J Cancer 2003; 88: 1702-7.

20. Grant WB. Role of solar UVB irradiance and smoking in cancer as inferred from cancer incidence rates by occupation in Nordic countries. Dermatoendocrinol 2012; 4: 203-11.

21. World Health Organization. Building blocks for tobacco control: a handbook. (Tools for advancing tobacco control in the 21st century). Geneva: WHO, 2004.

22. Ostwald C, Gogacz P, Hillmann T, Schweder J, Gundlach K, Kundt $G$ et al. p53 mutational spectra are different between squamous-cell carcinomas of the lip and the oral cavity. Int $\mathrm{J}$ Cancer 2000; 88: 82-6.

23. Lucena EES. Prevalência e fatores associados a lesões labiais e periorais decorrentes da exposição solar em trabalhadores de praia [dissertação]. Natal: Universidade Federal do Rio Grande do Norte; 2011.

24. Antoníades DZ, Styanidis K, Papanayotou P, Trigonidis G. Squamous cell carcinoma of the lips in a northern Greek population. Evaluation of prognostic factors on 5-year survival rate--I. Eur J Cancer B Oral Oncol 1995; 31B:333-9.

25. dos Santos LR, Cernea CR, Kowalski LP, Carneiro PC, Soto MN, Nishio S, et al. Squamous-cell carcinoma of the lower lip: a retrospective study of 58 patients. São Paulo Med J 1996; 114: 1117-26.

26. Vukadinovic M, Jezdic Z, Petrovic M, Medenica LM, Lens M, Vukadinovic M, et al. Surgical management of squamous cell carcinoma of the lip: analysis of a 10-year experience in 223 patients. J Oral Maxillofac Surg 2007; 65: 675-9. 